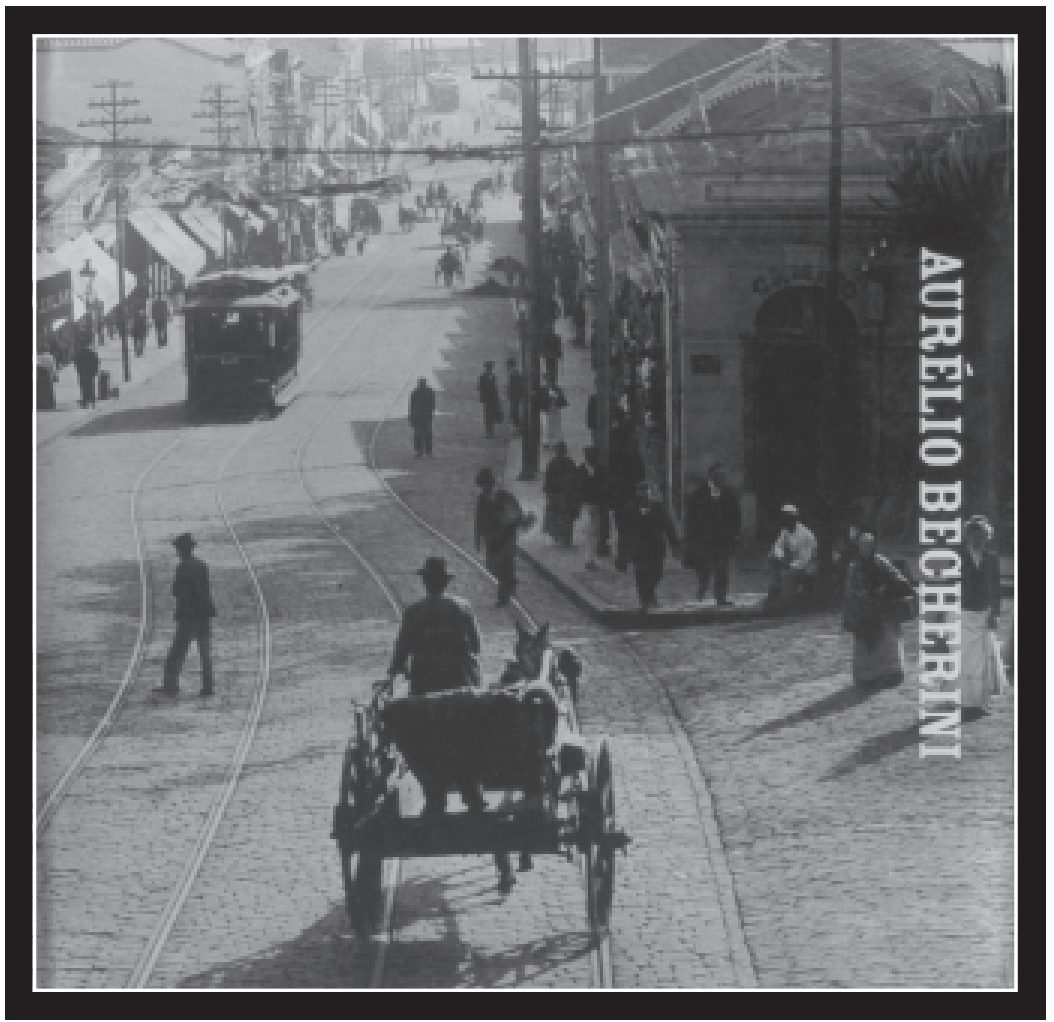

Aurélio Becherini (1879-1939). Textos: Rubens Fernandes Junior, Angela C. Garcia e José de Souza Martins. São Paulo: Cosac Naify, 2009, 236 páginas. 


\title{
São Paulo degustada aos poucos
}

\author{
MariaZaclis Veiga Ferreira*
}

A primeira vez que fui a São Paulo foi no início de 1980. Assusteime. A cidade possuía uma pulsação que eu, moradora do interior do Paraná, não consegui absorver. Os anos passaram e entre uma viagem e outra me apaixonei pela cidade, seus museus, praças, avenidas movimentadas, viadutos... Descobri que São Paulo é para ser degustada aos poucos.

Assim é o livro Aurélio Becherini, editado pela Cosac Naify em conjunto com a Secretaria Municipal de Cultura, o Departamento do Patrimônio Histórico e o Museu da Cidade de São Paulo, em comemoração aos 455 anos da cidade. Em uma edição primorosa, São Paulo do início do século XX se despe lentamente através das lentes de Aurélio Becherini (1879-1939), um italiano chegou ao Brasil por volta de 1900 e documentou a transformação da cidade.

Considerado o primeiro repórter fotográfico da imprensa paulistana publicou fotografias no O Estado de S. Paulo, Correio Paulistano, Jornal do Comércio e várias revistas como Cricri e Vida Doméstica. É dele a primeira "máquina de reportagem" que chegou a São Paulo. No capítulo intitulado O primeiro repórter fotográfico paulistano, Angela Garcia (2009, p.32) reproduz uma página da revista Atualidades Cinótica, de 1975, comemorativa aos 100 anos do jornal O Estado de S. Paulo (fundado em 1875, como A Província de S. Paulo). Nesta página, consta a "[...] máquina francesa, tamanho $13 \times 18 \mathrm{~cm}$, em formato de caixa, que usava as primeiras chapas de vidro fabricadas. [...] As reportagens realizadas por esta máquina, causaram grande sensação na época, marcando a éra (sic) fotográfica de reportagem em São Paulo".

\footnotetext{
* Jornalista, fotógrafa e professora. Mestre em Multimeios pela Universidade Estadual de Campinas (Unicamp). Doutoranda em Comunicação pela Universidade Trás-os-montes e Alto D'ouro (UTAD), de Portugal. Membro do Conselho de Coordenação do Curso de Comunicação Social Jornalismo da Universidade Positivo, de Curitiba. Vice-presidente do Instituto Cultural de Jornalistas do Paraná.
} 
As ruas retratadas por Becherini nas 193 imagens feitas entre 1904 e 1934 vão além de um registro duro e sintético. Em cada fotografia há uma série de informações que se complementam. O livro apresenta a organização espacial de uma cidade que vai se reconstruindo, na qual os carros são coadjuvantes em meio ao grande número de pedestres. Um prédio fechado, na rua do Carmo, que aguarda a sua vez de ser demolido, é espaço para a divulgação de unguentos, peças teatrais e cruzeiros para Argentina e Itália. A loja de luvas de pelica é pano de fundo para os homens que, invariavelmente de chapéu, deslocam-se na calçada.

$\mathrm{O}$ livro se divide em três partes. A primeira traz três textos que fazem referência ao fotógrafo e à importância de suas fotografias para melhor conhecer e entender São Paulo. O primeiro texto é Lições e demolições do olhar, assinado por Rubens Fernandes Filho. O segundo, de Angela C. Garcia, historia e classifica Aurélio Becherini como $O$ primeiro repórter fotográfico paulistano. José de Souza Martins assina o terceiro texto: O nascimento da vida cotidiana paulistana.

Na segunda parte do livro vemos as fotografias organizadas a partir do aspecto geográfico. A biografia de Becherini, bibliografia, índice de imagens por logradouro e versão dos textos em inglês completam a terceira parte. O projeto gráfico, de Eliane Ramos e Maria Carolina Sampaio, lembra páginas de jornal, divididas em colunas. Algumas fotografias ultrapassam a página e se completam na seguinte. O projeto ainda traz uma surpresa: a sobrecapa é um pôster da rua Direita esquina com a São Bento.

Os textos da primeira parte contextualizam e enriquecem o livro. Rubens Fernandes Junior é crítico e curador de fotografia e trata da construção técnica e estética do trabalho que ele chama de "lente transformadora". Lições e demolições do olhar apresenta também informações históricas e grandes nomes da fotografia da época. O artigo é ilustrado por belas reproduções de cartões de estúdios como o de Giovanni Sarracino, Michelle Rizzo e Oreste Cilento, envelopes de encomendas fotográficas e um exemplo das fichas de catalogação feitas pelo fotógrafo Benedito Junqueira Duarte nos anos 40. 
Fernandes Junior tece um elaborado apanhado dos fotógrafos que trabalharam na mesma época que Becherini e fizeram parte da documentação urbana que "se inicia exatamente nesse momento em que a cidade abandona seu traçado colonial e começa a se modificar dramaticamente". O fotógrafo destaca algumas imagens e conduz o leitor em algumas leituras pontuais como no caso da que ilustra o estúdio de fotografia Russo "[...] uma ampla visão do largo criado a partir da demolição do edifício do Barão de Tatuí, onde de novo se vislumbra no centro da imagem outro estúdio fotográfico. É como se Becherini estivesse pontuando a cidade homenageando os estúdios de fotografia". Seu texto finaliza com uma exaltação a Becherini: "[...] porque sua obra tão ampla e diversa de seus contemporâneos está pontuada pela urgência de produzir um documento histórico que transcenda seu tempo".

Uma compilação da dissertação de mestrado da arquiteta, fotógrafa e pesquisadora Angela Garcia é um rico histórico dos usos e costumes da imprensa. O texto $O$ primeiro repórter fotográfico paulistano traz reproduções de jornais nos quais fotografias de Becherini foram publicadas. Garcia aponta os temas tratados de maneira mais frequente pelos jornais entre as décadas de 10 e 20 . Na primeira fase as reportagens tinham um tom otimista quanto às inovações e construções. Esse tom se perdeu após os conflitos de 1924. Nas páginas 37 e 38, a autora destaca que: "Calçamentos nas ruas (que representariam benefícios aos cidadãos) e novos edifícios dividiam espaços com denúncias: 'Mau gosto' (17/5/ 1928), 'São Paulo perdeu a linha' (15/11/1928), 'tapumes na linha de passeio' (5/6/1929) [...]. Nesses casos a fotografia conferia visibilidade, credibilidade e comunicação como o seu público leitor, que se via, com tais publicações, representado pela imprensa."

O nascimento da vida cotidiana paulistana do professor emérito da Universidade de São Paulo (USP), José de Souza Martins, ressalta as transformações sociais e culturais da cidade. Na página 47 do livro, Martins destaca que: "Becherini fotografou o que restava da arquitetura e da mentalidade do Brasil colonial e escravista e o nascimento não só de uma cidade nova, mas de uma sociedade nova, nas novas formas e volumes 
das ruas e dos edifícios, na transitoriedade de pessoas e poderes por trás de janelas e de sacadas."

Acompanham esse texto fotografias que são recortadas e convidam o leitor a observar determinados quadros muito representativos. Na página 63 , por exemplo, a fotografia da rua General Carneiro, quando recortada destaca uma família. O olhar fixo e inquisitivo das quatro pessoas convida o leitor a perpetuá-los.

Alguns desses recortes vêm acompanhados de descrições como a do Viaduto do Chá de 1917, na qual

[...] vê-se lá longe, vindo dos lados da rua Líbero Badaró, pela calçada da esquerda, em direção ao Teatro São José, um homem sorridente que a lupa revela ser ninguém menos do que Cornélio Pires, conforme uma nota de Benedito Junqueira Duarte que analisou as fotos em 1924 e 1936. (MARTINS, 2009, p.48).

Martins (2009, p.50) ressalta que é nesse aspecto que

a fotografia de Becherini é singular e documental, porque documenta o que se vê que é a monumentalização da cidade, e o que não se vê, senão com a lupa de escrutinador, a cotidianização da cidade, na coexistência dos tempos, no progresso se insinuando entre as demoras da história, nas encenações particulares, nos gestos, no vestuário, na postura, na apresentação pessoal, na dissimulação e na correspondente apresentação pública de cada habitante.

Na segunda parte do livro estão as fotografias que descortinam uma cidade em transformação. O ensaio fotográfico foi ordenado por local e dentro dessa ordem se apresentam de maneira cronológica. Em várias fotografias vemos obras em andamento; prédios fechados esperam a vez de dar lugar às novas edificações exigidas pelo crescimento da metrópole; carroças e carros de aluguel disputam lugar nas ruas. Os ofícios da época se destacam nas placas da fábrica de luvas, da alfaiataria, das oficinas, das lojas de secos e molhados, das charutarias, das farmácias e padarias. 
O livro, belíssimo e muito bem acabado, reforça a importância da fotografia documental na qual o fotógrafo lança luz sobre as intrincadas relações sociais de uma cidade e seus viventes. $\mathrm{O}$ resgate feito no livro confere às fotografias um novo contexto, aberto às especulações da imaginação de cada leitor qualquer que seja sua intenção. É um convite não só aos paulistanos, mas aos fotógrafos, historiadores, estudantes, jornalistas, antropólogos e todos que tenham a curiosidade de compreender um pouco mais da estrutura sobre a qual se edificou o Brasil. 